\title{
Offline Learning Readiness during COVID-19 Pandemic: Indonesian' Parent Knowledge, Belief, and Attitude
}

\author{
Titin Sutini*(D), Anita Apriliawati(D), Medya Aprilia Astuti(D), Intan Trias Wulandari(D), Refina Tri Santi(D) \\ Department of Pediatric Nursing, Universitas Muhammadiyah Jakarta, South Tangerang, Indonesia
}

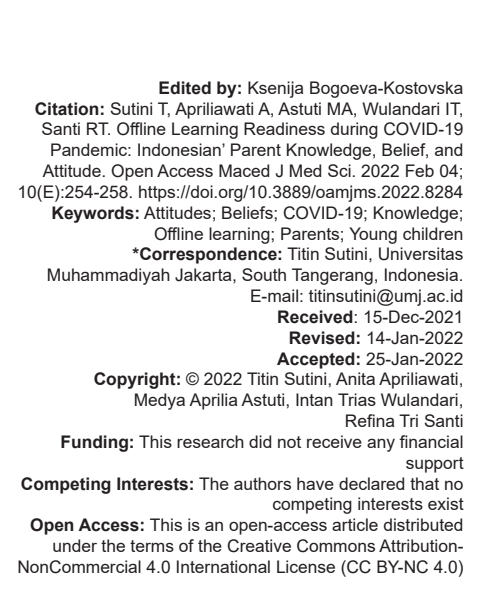

Introduction

The WHO declared the COVID-19 outbreak in Wuhan as an international Public Health Emergency of International on January 30, 2020. National governments have responded to this problem globally by imposing travel restrictions, lockdowns, occupational safety control, and facilities closures. More than $98.5 \%$ of the student population has been affected by the closure of pre-schools, schools, and colleges in 172 nations [1]. Indonesia is not an exception to this situation. Moreover, the Indonesian Ministry of Education (2020a) mandated all schools and institutions to discontinue face-to-face teaching and switch to online learning. To complete their education, students had to take online programs. Indonesian parents responded to the lockdown by providing their children with online education, as teachers and educational officials recommended. However, in Indonesian socio-cultural situations, it is not difficult to see how such influences on parents can lead to the adoption of online learning.
With the introduction of new communication technologies, online learning can create a dynamic, natural learning environment that fosters collaboration and interdependence among learners [2]. However, the studies have emphasized the primary challenges in developing a virtual education society with strong social engagement and participation [3], [4]. A lack of social interaction, involvement, and delayed response are essential considerations for some scholars [5]. Similarly, debates and criticisms have been leveled at young children's online courses. Some scholars [6], [7] emphasized their concerns about internet adverse consequences, internet addictions, social isolation, and inactive physical health issues. Others suggested that parents limit their children's online activity by setting up technology use rules and monitoring their children's media use [8].

While online learning may become more common in the future [9], parents are unsure if mobile gadgets are good or harmful to their children and how to use them [10], [11], [12]. For example, the EU kid's online study [11] found that parents with more significant income and education used various techniques and 
strategies to manage digital device limits, promoting offline activities for kids while restricting digital activities at home. Some parents-imposed rules and limits on how often and for how long their children might use digital devices, but they failed to realize the value of their role and involvement in their children's technology interactions [13], [14]. Early September 2021 began to open the school for offline learning with strict COVID-19 prevention protocol. However, this policy may cause parents to feel anxious and concerned about their children's health during face-to-face learning. The previous research has focused on parents' perspectives and practices toward their children's digital use in general, leaving their beliefs and attitudes concerning offline learning in the COVID-19 pandemic (after the second wave of COVID-19) unexplored. It is essential to look at parents' knowledge, beliefs, and attitudes about their kids' readiness for offline learning and how willing they are to make this big transition. Most extant research is Western-centric, excluding perspectives from Eastern countries, where cultures and educational beliefs may differ. This study addresses the following research questions through an online survey: 1) What were Indonesian parents' knowledge of offline learning for their young children? 2) What were Indonesian parents' beliefs about offline learning during the COVID-1? 3) What were Indonesian parents' attitudes toward offline learning for their young children? and 4) What were Indonesian parents' readiness toward offline learning for their young children?

\section{Methods}

\section{Study design}

Aquantitative method was used to attain the goals of this study. A survey is the best way to get information about many people quickly and efficiently [15]. In this study, a cross-sectional survey was used to collect data on COVID-19 in Indonesia. Survey Monkey was used to gather the data online. The invitation to participate was distributed through social media.

\section{Sample}

The sample in this study was parents (either mothers or fathers) who had children aged 6-12-years-old. The inclusion criteria were parents aged over 18-years-old had a gadget and willing to participate in this study. Parents who are unable to speak and write in Bahasa or had cognitive and metal problems were excluded from this study. The targeted sample size was 640 , which was calculated by determining the medium effect size with a $5 \%$ margin of error and a $95 \%$ confidence level [16], [17]. A convenience sampling technique was used in this study.

\section{Instruments}

Thirteen items were developed from prior research [18] and used to assess knowledge of the COVID-19. These items assess participant knowledge regarding COVID-19's clinical manifestations (Items 1-4), infection mechanisms (Items 5-8), and prevention and management (Items 9-13). These questions were answered as "true," "false," or "not sure." A correct response scored one point, whereas an incorrect/uncertain response scored zero. Higher scores indicated a higher level of knowledge. Parents' belief and attitude about offline learning were assessed using a 5-point Likert scale (with responses ranging from "strongly disagree" to "strongly agree"). The 27 questions are divided into three categories. Subscale one, which contains nine items, is about the advantages and disadvantages of offline learning. Parents were requested to compare online learning with the conventional face-to-face method. To measure readiness for offline learning, participants were asked yes/no questions about whether they were ready to go to school, wore a face mask while at school, and maintained proper hand hygiene, and limited social activities on a large scale.

\section{Procedure}

This study has been approved by the Ethical Committee of affiliated university (III/034.ELC/ $\mathrm{KEPK} / 2021)$ and permission to conducted study from school managers was obtained. This survey was performed between June 27 and July 3, 2021. An online survey utilizing Survey Monkey Advantage Annual was used as a substitute for a systematic nationwide sample technique. The poll was primarily disseminated through social media (Facebook, Twitter, and Instagram) and WhatsApp, the two most popular channels at the time. In Indonesia, Facebook and WhatsApp have been identified as two of the most popular communication and social networking sites [19]. Participants who agreed to engage in the survey voluntarily would click the "Next" option and be led to a self-administered survey to answer. We used multiple strategies to reach as many people as feasible within 1 week of data collection. An overall number of 800 people took part in the survey.

\section{Data analysis}

Percentages were used to represent categorical data, whereas means and standard deviations (SDs) represent continuous variables. We conducted a bivariate analysis using the student t-test and ANOVA for continuous data and the Chi-square test for categorical data. A linear regression model was employed to find readiness-related factors. $\mathrm{P}<0.05$ was considered to be statistically significant. SPSS 22.0 was used to analyze the data collected. 


\section{Results}

A total of 800 (response rate was $80 \%$ ) participated in the study. The average age was 34 $(S D=12.3), 60 \%$ were female and $54 \%$ worked in the public sector. Other demographic characteristics are shown in Table 1.

Table 1: Differences in readiness to offline learning according to the general characteristics of study participants $(n=800)$

\begin{tabular}{llllll}
\hline Variable & Categories & $\mathrm{n}(\%)$ & \multicolumn{4}{l}{ Readiness to offline learning } \\
\cline { 4 - 6 } & & & $\mathrm{M} \pm \mathrm{SD}$ & $\mathrm{t}$ or F or r & $\mathrm{P}$ \\
\hline Gender & Men & $320(40)$ & $10.73 \pm 3.15$ & 0.332 & 0.356 \\
& Women & $480(60)$ & $9.29 \pm 2.54$ & & \\
Education level & Below secondary level & $280(35)$ & $10.73 \pm 7.07$ & 0.603 & 0.549 \\
& Above secondary level & $520(65)$ & $11.71 \pm 6.29$ & & \\
Working status & $\begin{array}{l}\text { Public sector } \\
\text { Private sector }\end{array}$ & $432(54)$ & $11.32 \pm 4.68$ & 0.401 & 0.620 \\
& Household & $160(25)$ & $10.77 \pm 3.35$ & & \\
Knowledge & & & $10.3 \pm 3.27$ & 0.104 & 0.089 \\
Belief & & & $3.88 \pm 0.12$ & 0.337 & 0.001 \\
Attitude & & & $3.78 \pm 0.14$ & 0.309 & 0.001 \\
\hline
\end{tabular}

Participants had an average knowledge score of $10.3(S D=3.27$, with a range of $0-13)$ (Table 1$)$. The total correct answer rate for the knowledge questionnaire was $79.2 \%$, with correct answer rates ranging from $45.45 \%$ to $100 \%$ for all participants. Approximately $75.2 \%$ of participants achieved a score of 10 or higher. Parental attitudes concerning offline schooling versus online learning were examined concerning the advantages and disadvantages of offline schooling versus online learning. This scale had a mean of 3.88 and a SD of 0.12 (Table 1). Most participants (56\%) agreed that offline learning provides better material, better learning results $(62.0 \%)$, and is more efficient than internet learning $(45 \%)$. Most parents were neither in agreement nor in disagreement with the comments on the advantages and disadvantages of offline learning; this indicates that they have a neutral view of the worth of online education. Second, most participants felt confident with offline learning (78\%). The mean score was $3.78(\mathrm{SD}=0.14)$ (Table 2), while the preparedness score was $3.45(\mathrm{SD}=0.89)$ (Table 1$)$. Approximately $80 \%$ of parents believe their child is ready for offline study, $93 \%$ wear a face mask to school, $82 \%$ maintain proper hand hygiene, and $85 \%$ limit large scale social activities.

Table 2: Multiple regression of factors associated with readiness to offline learning $(n=800)$

\begin{tabular}{llll}
\hline Variable & $\mathrm{B}(\mathrm{SE})$ & $95 \% \mathrm{Cl}$ & $\mathrm{p}$-value \\
\hline Age (year) & $0.154(0.05)$ & $0.11-1.34$ & 0.672 \\
Gender (male vs. female) & $-0.88(1.32)$ & $-2.74-2.65$ & 0.354 \\
Education level & $0.109(0.08)$ & $0.87-1.65$ & 0.389 \\
Place of work (public vs. private) & $-0.35(1.43)$ & $-2.47-3.18$ & 0.805 \\
Knowledge & $1.16(1.35)$ & $-1.51-3.82$ & 0.109 \\
Belief & $2.89(1.35)$ & $1.02-5.57$ & 0.001 \\
Attitude & $3.04(1.20)$ & $1.17-7.02$ & 0.001 \\
\hline
\end{tabular}

In the multivariable analysis, we found that, after adjusting for all cofounders in the final model, attitude $(\beta=3.04$ and $p=0.001)$ and belief $(\beta=2.89$ and $p=0.001$ ) were the factors associated with readiness to offline learning outbreak COVID-19 pandemic (Table 2).

\section{Discussion}

This study found that most parents had a moderate level of knowledge toward COVID-19. Nonetheless, correct COVID-19 knowledge rates varied substantially, showing that some individuals had an extensive understanding of the condition, but others did not. These findings may imply a lack of timely and credible information on the pathogen. This knowledge variety may reflect the existing COVID-19 data landscape in the country. Although health authorities have been consistently sharing COVID-19 information since the disease was first diagnosed in Indonesia, there has also been an increase in incorrect and inaccurate material [20], [21]. Information overload may have led to confusion and difficulties verifying facts.

Parents expressed reasonably high attitudes toward the importance of offline learning.

During the COVID-19 pandemic, this study was the first to look into Indonesian parents' beliefs and attitudes about offline learning. Parents believe that traditional learning is preferable to online learning in early childhood educational settings. A previous study argued that online education lacked a learning atmosphere and social connections to interest young children, resulting in poor learning outcomes [22]. These good attitudes toward offline learning may be linked to two primary justifications. The first is that COVID-19 has decreased, leading to offline learning. Second, parents' conventional conceptions of childhood and expectations for early childhood educational methods, such as unstructured play and time spent outside, should be maintained [23]. Parents and teachers often think that young children should not use digital technology, making it difficult and confusing for people who want to use digital technology in young children's learning [12], [24]. However, through parental education or family-school partnership initiatives, these Indonesian parents can learn new concepts such as "childhoods," "learning," and "play."

Almost all parent-reported ready for offline learning and this readiness score was significantly associated with belief and attitude. This favorable outcome may be explained by the falling trend in COVID-19 cases and the efficacy of COVID-19 vaccinations. People are more likely to take preventative measures if they believe that the health threat is significant, believe they are vulnerable, and believe there are fewer hurdles than benefits to doing so [25]. Findings from this study are consistent with some Western studies that found that parents in EU countries [11], [26] and Australia [26] were concerned about online risks and too much time spent on the internet with their children, even though this study was conducted in a different context and at a different time (COVID-19). Furthermore, parents felt incapable of educating their young children because their traditional 
position was not that of a child's teacher, and they had not been taught to do so. Thus, they lacked confidence in teaching their children at home, believing that 'teachers had more control over their students' learning environments" [22]. As a result, they were overjoyed to be able to send their children back to school.

\section{Limitations}

Convenience sampling was used to gather data for the study, and then shared on various social media sites (WhatsApp, Facebook, and Twitter). As a result, there is a risk of bias because less fortunate people might not have participated in the study. A more systematic and comprehensive sampling approach is needed to increase the representativeness and generalizability of the findings. The second limitation concerns the instrument that was employed in this study. Determining instrument validity and reliability would have resulted in a more robust instrument. In addition, the present study's limitations include the likelihood of individuals providing socially desired responses. Because this study used self-reported data, individuals may have positively answered belief and attitude questions based on expectations [27].

\section{Conclusions}

This study found that the most of parents had a moderate level of knowledge toward COVID-19, expressed reasonably high attitudes toward the importance of offline learning, and parent-reported ready for offline learning. Parent readiness score was significantly associated with belief and attitude. The findings indicate that Indonesian parents have an adequate degree of knowledge, belief, and attitude regarding their willingness to engage in offline learning during the COVID-19 pandemic. Nonetheless, regular messaging from the government and health authorities is critical for increasing public awareness and comprehension of COVID-19. Individuals may also benefit from targeted health education programs to strengthen COVID-19 knowledge, belief, and preparation for offline learning during pandemic COVID-19.

\section{References}

1. UNESCO. COVID-19 Educational Disruption and Response. UNESCO; 2020. Available from: https://en.unesco.org/covid19/ educationresponse [Last accessed on 2021 Mar 25].

2. Aldhafeeri FM, Khan BH. Teachers' and students' views on e-learning readiness in Kuwait's secondary public schools.
J Educ Technol Syst. 2016;45(2):202-35. https://doi. org/10.1177/0047239516646747

3. Chen P-SD, Lambert AD, Guidry KR. Engaging online learners: The impact of Web-based learning technology on college student engagement. Comput Educ. 2010;54(4):1222-32.

4. O'Doherty D, Dromey M, Lougheed J, Hannigan A, Last J, McGrath D. Barriers and solutions to online learning in medical education-an integrative review. BMC Med Educ. 2018;18(1):1-11.

5. Khurana C. Exploring the Role of Multimedia in Enhancing Social Presence in an Asynchronous Online Course. Canada: Rutgers University Graduate School New Brunswick; 2016.

6. Werner EA, Gustafsson HC, Lee S, Feng T, Jiang N, Desai P, et al PREPP: Postpartum depression prevention through the motherinfant dyad. Arch Womens Ment Health. 2016;19(2):229-42. https://doi.org/10.1007/s00737-015-0549-5 PMid:26231973

7. Radesky JS, Peacock-Chambers E, Zuckerman B, Silverstein M. Use of mobile technology to calm upset children: Associations with social-emotional development. JAMA Pediatr. 2016;170(4):397-9. https://doi.org/10.1001/ jamapediatrics.2015.4260

PMid:26928293

8. Nouwen M, Zaman B. Redefining the role of parents in young children's online interactions. A value-sensitive design case study. Int J Child Comput Interact. 2018;18:22-6. https://doi. org/10.1016/j.jijcci.2018.06.001

9. Franklin TO, Burdette P, East T, Mellard DF. Parents' Roles in their Child's Online Learning Experience. University of Kansas Center on Online Learning and Students with Disabilities; 2015.

10. Radesky JS, Eisenberg S, Kistin CJ, Gross J, Block G, Zuckerman B, et al. Overstimulated consumers or nextgeneration learners? Parent tensions about child mobile technology use. Ann Fam Med. 2016;14(6):503-8. https://doi. org/10.1370/afm.1976

PMid:28376436

11. Livingstone S, Mascheroni G, Dreier M, Chaudron S, Lagae K How Parents of Young Children Manage Digital Devices at Home: The Role of Income, Education and Parental Style; 2015.

12. Erdogan $\mathrm{NI}$, Johnson JE, Dong PI, Qiu Z. Do parents prefer digital play? Examination of parental preferences and beliefs in four nations. Early Child Educ J. 2019;47(2):131-42.

13. Plowman L, McPake J, Stephen C. Extending opportunities for learning: the role of digital media in early education. In: Contemporary Debates in Childhood Education and Development. Milton Park, Abingdon-on-Thames: Routledge; 2012. p. 109-18.

14. Hatzigianni M, Kalaitzidis I. Early childhood educators' attitudes and beliefs around the use of touchscreen technologies by children under three years of age. $\mathrm{Br} \mathrm{J}$ Educ Technol. 2018;49(5):883-95.

15. Jones TL, Baxter MA, Khanduja V. A quick guide to survey research. Ann R Coll Surg Engl. 2013;95(1):5-7. https://doi.org/ $10.1308 / 003588413 \times 13511609956372$ PMid:23317709

16. Oakland GB. Determining sample size. Can Entomol 1953;85(3):108-13

17. Conroy R. Sample Size A Rough Guide; 2015. Avaialble from: http//www.beaumontethicsie/docs/application/ samplesizecalculationpdf [Last accessed on 2021 Mar 25].

18. Zhong BL, Luo W, Li HM, Zhang QQ, Liu XG, Li WT, et al. Knowledge, attitudes, and practices towards COVID-19 among Chinese residents during the rapid rise period of the COVID-19 outbreak: A quick online cross-sectional survey. Int J Biol Sci. 2020;16:1745-52. https://doi.org/10.7150/ijbs.45221 PMid:32226294 
19. Malaysian Communications and Multimedia Commission. Internet Users Survey 2018: Statistical Brief Number TwentyThree. Internet Users Survey. Malaysian Communications and Multimedia Commission; 2018. p. 1-39.

20. Saifuddin: It's a National Effort to Fight Fake News during COVID-19, MCO. Malay Mail; 2020. Available from: https:// www.malaymail.com/news/malaysia/2020/04/11/saifuddinits-a-national-effort-to-fight-fake-news-during-covid-19mco/1855779 [Last accessed on 2020 Apr 12].

21. Parzi MN. Five More Probed for Spreading Fake News on COVID-19. New Straits Times; 2020. Available from: https:// www.nst.com.my/news/crime-courts/2020/03/577561/fivemore-probed-spreading-fake-news-covid-19 [Last accessed on 2020 Apr 12]

22. Dong C, Mertala P. Two worlds collide? The role of Chinese traditions and Western influences in Chinese preservice teachers' perceptions of appropriate technology use. $\mathrm{Br} \mathrm{J}$ Educ Technol. 2021;52(1):288-303.

23. Stephen C, Edwards S. Young Children Playing and Learning in a Digital Age: A Cultural and Critical Perspective. Milton Park, Abingdon-on-Thames: Routledge; 2017.

24. Dong C, Mertala P. Two worlds collide? The role of Chinese traditions and Western influences in Chinese preservice teachers' perceptions of appropriate technology use. $\mathrm{Br} \mathrm{J}$ Educ Technol. 2021;52(1):288-303.

25. Syed-Abdul S, Gabarron E, Lau A. Participatory Health through Social Media. Cambridge, Massachusetts: Academic Press; 2016.

26. Australian Government. eSafetyparents; 2019. Available from: https://www.esafety.gov.au/parents [Last accessed on 2021 Mar 25]

27. Van de Mortel TF. Faking it: Social desirability response bias in self-report research. Aust J Adv Nurs. 2008;25(4):40-8. 